\title{
Mean Change in Refractive Status after Levator Muscle Resection in Patients of Simple Congenital Ptosis
}

\author{
Rana Muhammad Mohsin Javaid ${ }^{1}$, Ch. Nasir Ahmad ${ }^{2}$, Rehab Habib ${ }^{3}$ \\ Asad Aslam Khan ${ }^{4}$, Kashif Siddique ${ }^{5}$ \\ ${ }^{1-5}$ Department of Ophthalmology, KEMU, Lahore
}

\begin{abstract}
Purpose: To determine the mean change in refractive status after Levator muscle resection in patients of simple congenital ptosis.
\end{abstract}

Study Design: Quasi Experimental study.

Place and Duration of Study: This study was carried out at Institute of Ophthalmology, King Edward Medical University, Mayo Hospital Lahore, from 2014 to 2015.

Material and Methods: Fifty patients were selected under the age of 12 years with no sex predilection presenting with simple congenital ptosis of pupil sparing type. Patients with neurogenic, aponeurotic ptosis, mechanical ptosis, Blepharophimosis syndrome, patients with previous failed ptosis surgery and patients with corneal anomalies were excluded. After history and examination, Cycloplegic retinoscopy was done, which was repeated after surgical intervention. All interventions were done by a single ophthalmic surgeon. The patients were examined and discharged on the second post operative day. All data including preoperative and postoperative recordings of spherical and cylindrical values were collected on a self-designed proforma. Follow up period was extended to 3 months. At $3^{\text {rd }}$ month cycloplegic retinoscopy was done and change in character of refractive status was analyzed. Mean change in refractive status was calculated by difference of preoperative and postoperative sphere and cylinder values.

Results: Mean age of patients was $4.26 \pm 3.78$ years. Mean change in spherical value after treatment was 0.447 \pm 0.339 . This difference was statistically significant with $p$-value $=0.000$. While mean change in cylindrical value after treatment was $0.640 \pm 0.580$. This difference in cylinder value after treatment was also statistically significant with $p$-value $=0.000$.

Conclusion: Levator muscle resection has a significant effect on refractive status of the patients with congenital ptosis.

Key Words: Refractive error, Levator muscle resection, Congenital, Ptosis.

How to Cite this Article: Javaid RMM, Ahmad CN, Habib R, Khan AA, Siddique K. Mean Change in Refractive Status after Levator Muscle Resection in Patients of Simple Congenital Ptosis. Pak J Ophthalmol.2020; 36 (1):4852.

DOI: https://doi.org/10.36351/pjo.v36i1.996

\section{INTRODUCTION}

Congenital ptosis is a common condition in pediatric

Correspondence to: Rana Muhammad Mohsin Javaid Vitreo-retina Fellow, Mayo Hospital, KEMU, Lahore Email:Imdc99@hotmail.com population visiting Oculoplasty clinics. It is more common than acquired Blepharoptosis. Surgical repair is challenging and recurrence, necessitating more than one operation, is common. Children often require close follow-up post operatively because changes in refractive error have been reported following ptosis 
surgery.

Simple myogenic congenital ptosis is the commonest type in pediatric population ${ }^{1,2}$. Pediatric ptosis is much more challenging and sensitive than adult ptosis as refractive errors with consequent possible amblyopia may be associated with it $^{3}$. Anisometropia is the disparity in refractive status of both eyes. Anisometropic amblyopia may develop and progress rapidly during early childhood.

Pediatric ptosis can lead to reduction of visual potential albeit amblyopia by two means; by directly obstructing the visual axis in case of pupil obscuring ptosis; or by mechanically altering the shape of cornea which leads to astigmatism ${ }^{4}$.

In one study of patients with unilateral ptosis, the difference in refractive state of both eyes was more than 1 diopter cylinder that was enough to cause amblyopia and permanent visual damage ${ }^{5}$.

Berry Brincat and Willshaw reported that $18.7 \%$ pediatric patients of simple congenital ptosis had visually significant refractive errors ${ }^{5}$. Drooping of the lid can be addressed surgically by Levator muscle resection or sling suspension of the upper $\operatorname{lid}^{6,7}$. Sling surgery can be executed by using natural material or artificial suspenders.

Klimek DL studied refractive status before and after Levator resection and mean spherical change of $1.23 \pm 0.875$ diopters and mean cylindrical change of $0.83 \pm 0.75$ diopters was present after 20 months follow-up ${ }^{8}$. We reviewed the patient at 03 months by presuming that change in refractive status will be the same as after 20 months' follow-up.

Pupil obscuring ptosis is always an indication for early surgical intervention but we studied the patients of pupil sparing ptosis in which lid pressure is thought to be the cause of astigmatism and surgical intervention might play an important role in preventing amblyopia. By doing this study especially in our part of the world the results of this study can generate data for further research.

\section{MATERIAL AND METHODS}

This was a Quasi Experimental study conducted at Eye unit-III, Institute Of Ophthalmology, King Edward Medical University, Mayo Hospital Lahore. The patients were admitted from Eye OPD of Mayo Hospital Lahore by non-probability convenience sampling. Study was completed in 6 months i.e. from
November 2014 to May 2015. Total 50 patients were included in the study. Sample size of 50 cases was calculated with $95 \%$ confidence level, $\mathrm{d}=0.25$ and taking expected mean \pm S.D of mean change in refractive error i.e. $1.23 \mathrm{D} \pm 0.875$ (sphere) in patients with simple congenital ptosis undergoing ptosis surgery (unilateral Levator resection) ${ }^{9}$. Patients under the age of 12 years with no sex predilection presenting with simple congenital ptosis of pupil sparing type (assessed by birth history, absence of upper lid crease with no systemic association e.g. Chronic progressive external ophthalmoplegia etc. by a senior pediatric ophthalmologist) were included. Patients of other causes of ptosis like neurogenic, aponeurotic and mechanical ptosis (assessed by senior Paediatric Ophthalmologist and senior Neurologist), patients having ptosis associated with syndromes e.g. Blepharophimosis syndrome, patients with previous failed ptosis surgery and patients with corneal anomalies like microcornea, megalocornea, anterior segment dysgenesis and previous anterior segment surgeries were excluded. Cycloplegic retinoscopy was done before and after surgical intervention for simple congenital ptosis to determine refractive status. After briefing the merits and demerits of the treatment to parents of the patients, a written informed consent was taken. All the interventions were done by a single senior pediatric ophthalmic surgeon. Optical correction after cycloplegic retinoscopy with $1 \%$ cyclopen with glasses was done on scheduled visit. Levator muscle resection under general anaesthesia was carried out. The patients were examined and discharged on the second post-operative day. All data including pre-operative and post-operative recordings of spherical and cylindrical values were collected on a self-designed proforma. Follow up period was extended to 3 months. At $3^{\text {rd }}$ month cycloplegic retinoscopy was done and change in character of refractive status (spherical and cylindrical value) was compiled and analyzed. Mean change in refractive status was calculated by difference of pre-operative and post-operative sphere and cylinder values.

Data was entered and analyzed using computer program SPSS version-16. Descriptive statistics were applied to determine the mean and standard deviation (SD) for quantitative variables like age and pre and post-operative refractive status in terms of sphere and cylinder values. Qualitative variables like gender were presented in the form of frequency and percentages. Paired ' $t$ ' test was applied to compare the pre and postoperative change in refractive status (sphere and 
cylinder values). P-value $\leq 0.05$ was considered significant.

\section{RESULTS}

Mean age of patients was $4.26 \pm 3.78$ years. Gender distribution of patients showed that there were 35 male and 15 female patients. Mean sphere before treatment was $1.119 \pm 0.236$ and after treatment was $1.566 \pm$ 0.238 . Mean change in sphere after treatment was $0.447 \pm 0.339$. This difference in sphere was statistically significant ( $\mathrm{p}$-value $=0.000$ ). Mean cylindrical value before treatment was $-0.360 \pm 0.127$ and after treatment was 0.280- \pm 0.120 . Before treatment, minimum and maximum cylindrical values were -2.00 and 1.25 while after treatment, minimum and maximum cylindrical value was -1.75 and 2.25 respectively. Mean change in cylinder after treatment was $0.640 \pm 0.580$. This difference in cylinder after treatment was statistically significant ( $\mathrm{p}$-value = 0.000).

Table 1: Pre \& Post operative sphere and cylinder value.

\begin{tabular}{lcccc}
\hline & $\begin{array}{c}\text { Pre } \\
\text { Operative }\end{array}$ & $\begin{array}{c}\text { Post } \\
\text { Operative }\end{array}$ & $\begin{array}{c}\text { Mean } \\
\text { Change }\end{array}$ & $\begin{array}{c}\text { p- } \\
\text { value }\end{array}$ \\
\hline $\begin{array}{l}\text { Sphere } \\
\text { Value }\end{array}$ & $1.11 \pm 1.67$ & $1.56 \pm 1.68$ & $-0.44 \pm 0.33$ & 0.000 \\
$\begin{array}{l}\text { Cylinder } \\
\text { Value }\end{array}$ & $-0.36 \pm 0.89$ & $0.28 \pm 0.85$ & $-0.64 \pm 0.580$ & 0.000 \\
\hline
\end{tabular}

\section{DISCUSSION}

Blepharoptosis is a common eyelid problem. Degree of Levator function determines the choice of operation. Levator resection is employed for cases with good Levator function while frontalis sling is reserved for patients with poor Levator function. Many surgeons prefer Levator resection in eyes with Levator function greater than $4 \mathrm{~mm}$ and most of them believe that Levator resection yields a better lid contour and position as compared to frontalis sling ${ }^{9}$.

Children with congenital ptosis have a higher incidence of clinically significant astigmatism in the ipsilateral eye and are known to have an increased incidence of strabismus and amblyopia ${ }^{10-12}$. These children often require post-operative refractive correction and amblyopia therapy. Close follow-up is needed postoperatively as well because changes in refractive error have been reported following ptosis surgery.
Ptosis repair can be both challenging and frustrating, especially given ever-increasing demands for an optimal cosmetic surgical result ${ }^{13,14}$. The diagnosis and management of pediatric ptosis presents challenges because of difficulties in performing preoperative examinations ${ }^{13}$. The timing for surgical treatment varies depending on age, severity and laterality. The ideal procedures in ptosis surgery are those that disturb normal anatomy the least and also allow for good results ${ }^{15,16}$.

Cates and Tyers performed Levator resection in 100 patients less than 7 years of age with congenital ptosis and having a levator function of at least $4 \mathrm{~mm}$. They reported a $75 \%$ success rate, which was defined as a post-operative lid margin position within $1 \mathrm{~mm}$ of normal. In that study, the most common complication was under-correction (19\%) and overcorrection was less common $(7 \%)$. They found that the pre-operative amount of levator function was the strongest predictor of a favorable outcome following levator resection surgery ${ }^{17}$.

Stark and Walther reviewed 54 patients who had congenital ptosis surgery to determine the incidence of refractive errors, strabismus, and amblyopia. Of these patients, $70 \%$ had significant refractive error, $43 \%$ had astigmatism of more than $1.0 \mathrm{D}, 55 \%$ had anisometropia of more than $1.25 \mathrm{D}$ sphere or $0.75 \mathrm{D}$ cylinder, $27.5 \%$ had strabismus, and $50 \%$ had amblyopia $^{18}$. In cases of unilateral Ptosis, the drooping eye has more amblyogenic refractive error than the normal eye ${ }^{19,20}$.

Cadera et al reviewed 88 eyes that had undergone unilateral or bilateral ptosis surgery using either fascia lata sling or levator resection. Thirty-six normal eyes were used as controls. Twenty-nine eyes underwent levator resection, whereas 59 eyelids received a frontalis sling. Twelve months post-operatively, 58 of 88 eyes underwent cycloplegic refraction. Of the operated eyes, $35(40 \%)$ had a pre-operative cylinder greater than $1.00 \mathrm{D}$. There was a significant difference in the mean cylindrical error: the operated eyes showed a mean increase in cylinder of $0.30 \mathrm{D}$, whereas the control group demonstrated a mean decrease of $0.15 \mathrm{D}$ at 12 months postoperatively ${ }^{11}$.

Cadera et $\mathrm{al}^{11}$ compared those eyes that had undergone unilateral surgery and had a change in cylinder of at least $0.75 \mathrm{D}$ with their own matched control (contralateral eye). There were 12 eyes that met these criteria, but only 8 of these had unilateral 
levator resections. The authors reported a "noteworthy" difference between the control and operated eyes, with the operated eye having a greater change in each case, but no statistics were provided. They also noted that patients older than 4 years at the time of surgery showed an increase in mean cylinder $(0.50 \mathrm{D})$, whereas those younger than 4 years had a decrease in mean cylinder $(0.20 \mathrm{D})$. Because of this, they proposed early surgery in patients with large amounts of cylinder in the eye with ptosis in order to lessen the amount of post-operative astigmatism and eliminate the need for glasses and amblyopia therapy ${ }^{11}$. In a study done by Klimek DL refractive status was studied before and after levator resection and mean spherical change of $1.23 \pm 0.875$ diopters and mean cylindrical change of $0.83 \pm 0.75$ diopters was present after 20 months follow-up ${ }^{8}$. When mean refractive errors (sphere and cylinder) were compared inter-ocularly, no statistically significant difference was found between eyes with associated ptosis and control eyes pre-operatively or post-operatively. No association was found between age at the time of surgery or the amount of pre-operative ptosis and the amount of post-operative cylindrical change.

Our results are consistent with the results reported by Klimek DL for change in cylindrical value post operatively. However, Klimek DL reported insignificant change for spherical value postoperatively which is not consistent with the results of this study as our results showed change in both sphere and cylinder values.

No study was done in our population, which addressed the effectiveness of levator muscle resection and change in refractive error post-operatively. A gap exists in this domain for treating congenital ptosis with levator muscle resection. However, these results have shown the effectiveness of this procedure as well as addressed the significant change in refractive error. With the help of these results, it is clear that use of levator muscle resection in patients improves the cosmetic appearance and prevents amblyopia by clearing the visual axis in severe ptosis. Treatment of ptosis related astigmatism in mild to moderate ptosis with glasses is essential.

\section{CONCLUSION}

Results of this study showed that levator muscle resection has a significant effect on refractive status of the patients with congenital ptosis.

\section{Ethical Approval}

The study was approved by the Institutional review board/Ethical review board.

\section{Conflict of Interest}

Authors declared no conflict of interest.

\section{Authors' Designation and Contribution}

Rana Muhammad Mohsin Javaid; Vitreo-retina Fellow: Literature Search, Manuscript write-up.

Chaudhary Nasir Ahmad; Associate Professor: Study Concept, final review.

Rehab Habib; Demonstrator Psychology: Data Collection, final review.

Asad Aslam Khan; Professor: Study Design, final review.

Kashif Siddique; Biostatistician: Data analysis, final review.

\section{REFERENCES}

1. Kanski JJ. B. Ptosis, In: Clinical Ophthalmology. 7th ed. China: Butterworth Heinemann, 2011: p. 39-47.

2. Griepentrog GJ, Diehl NN, Mohney BG. Incidence and demographics of childhood ptosis. Ophthalmology, 2011; 118 (6): 1180-3.

3. Srinagesh V, Simon JW, Meyer DR, Zobal-Ratner J. The association of refractive error, strabismus, and amblyopia with congenital ptosis. J Am Assoc Ped Ophthalmoland Strab. 2011; 15 (6): 541-4.

4. Zinkernagel MS, Ebneter A, Ammann-Rauch D. Effect of upper eyelid surgery on corneal topography. Arch Ophthalmol. 2007; 125 (12): 1610-2.

5. Berry-Brincat A, Willshaw H. Paediatric blepharoptosis: a 10-year review. Eye. 2008; 23 (7): 1554-9.

6. Allard FD, Durairaj VD. Current techniques in surgical correction of congenital ptosis. Middle East Afr. J Ophthalmol. 2010; 17 (2): 129.

7. Abrishami A, Bagheri A, Salour H, Aletaha M, Yazdani S. Outcomes of Levator resection at tertiary eye care center in Iran: a 10-year experience. Korean J Ophthalmol. 2012; 26 (1): 1-5.

8. Klimek DL, Summers CG, Letson RD, Davitt BV. Change in refractive error after unilateral Levator resection for congenital ptosis. JAAPOS. 2001; 5 (5): 297-300.

9. Keyhani K, Ashenhurst M. Modified technique and ptosis clamp for surgical correction of congenital pediatric ptosis by anterior Levator resection. Arch Facial Plast Surg. 2007; 23 (3): 156-61. 
10. Hoick DE, Dutton JJ, Wehrly SR. Changes in astigmatism after ptosis surgery measured by corneal topography. Ophthal Plast Recons Surg. 1998; 14 (3): 151-8.

11. Cadera W, Orton R, Hakim O. Changes in astigmatism after surgery for congenital ptosis. J Pediat Ophth Strab. 1991; 29 (2): 85-8.

12. Lee DS, Kim JM, Woo KI, Chang HR. Changes in Astigmatism after Surgery for Congenital Ptosis. J Korean Ophthalmol Soci. 2006; 47 (9): 1459-64.

13. Ungerechts R, Grenzebach U, Harder B, Emmerich K. Causes, diagnostics and therapy for paediatric ptosis. Klinische Monatsblatter fur Augenheilkunde. 2012; 229 (1): 21-7.

14. Ng J HM. Ptosis repair. Facial Plast Surg. 2013; 29 (1): 22-5.

15. Mesa GJ, Mascaró ZF, Muñoz QS, Prat BJ, Arruga GJ. Upper eyelid surgery for treatment of congenital blepharoptosis. Cirugia pediatrica: organo oficial de la Sociedad Espanola de Cirugia Pediatrica. 2007; 20 (2):
91-5.

16. Meyer DR, Linberg JV, Wobig JL, McCormick SA. Anatomy of the orbital septum and associated eyelid connective tissues: implications for ptosis surgery. Ophth Plast Recons Surg. 1991;7 (2): 104-13.

17. Cates CA, Tyers AG. Outcomes of anterior Levator resection in congenital blepharoptosis. Eye, 2001; 15 (6): 770-3.

18. Stärk N, Walther C. Refractive errors, amblyopia and strabismus in congenital ptosis. Klinische Monatsblatter fur Augenheilkunde. 1984; 184 (1): 37-9.

19. Paik JS, Kim SA, Park SH, Yang SW. Refractive error characteristics in patients with congenital blepharoptosis before and after ptosis repair surgery. BMC Ophthalmol. 2016; 16: 177. Doi:10.1186/s12886016-0351-9.

20. Maseedupally V, Gifford P, Swarbrick H. Variation in normal corneal shape and the influence of eyelid morphometry. Optom Vis Sci. 2015; 92 (3): 286-300. 